\title{
TESTIMONIO Y REPRESENTACIÓN DURANTE EL SITIO DE LA INTENDENCIA DE LA PAZ EN 1782 EN LAS POSTRIMERÍAS DE LA INSURGENCIA DE TÚPAC AMARU II
}

Testimony and representation during the siege of the intendencia of la paz in 1782 in the final stage of the insurgency of Tupac Amaru II

Ricardo Pinto-Bazurco Mendoza ${ }^{1}$

RESUMeN

Desde el punto de vista histórico el análisis de fuentes "no oficiales" permite escudriñar algunos hechos y personajes anónimos inmersos en su propia dinámica y significado. Como es el caso que se recoge del testimonio epistolar de un poblador de la Intendencia de La Paz (Virreinato del Río de la Plata) en 1782 durante la etapa final del levantamiento iniciado por Túpac Amaru II. Cuyo testimonio, además, contribuye y enriquece el análisis del proceso de construcción de los sistemas de representaciones en medio de un periodo de grandes cambios e impacto social en las postrimerías del siglo XVIII en el sur andino.

Palabras claves: Túpac Amaru II, insurgencia, intendencia, sitio, La Paz, siglo XVIII.

\section{Abstract}

From a historical point of view, the analysis of "unofficial" sources allows some facts and anonymous characters immersed in their own dynamics and meaning to be searched. As is the case that is collected from the epistolar testimony of a settler of the Intendencia de La Paz (Viceroyalty of the Río de la Plata) in 1782 during the final stage of the uprising initiated by Tupac Amaru II. Whose testimony also contributes to and enriches the analysis of the process of building representation systems in the midst of a period

Historiador y gestor cultural por la Universidad Nacional Mayor de San Marcos. Miembro del Instituto Raúl Porras Barrenechea. Centro de Altos Estudios y de Investigaciones Peruanas y miembro de la comisión de historia de la Benemérita Sociedad Fundadores de la Independencia, Vencedores el 2 de Mayo 1866 y Defensores Calificados de la Patria.

of great changes and social impact in the late eighteenth century in the Southern Andean.

Keywords: Tupac Amaru II, insurgency, intendencia, siege, La Paz, 18th century

\section{INTRODUCCIÓN}

$\mathfrak{E}$ levantamiento o revolución de Túpac Amaru II, que inició en 1780, ha sido sujeto a innumerables escrutinios desde diferentes enfoques. Pasando por aquel reverdecer que el "velasquismo"(1) imprimió al significado del levantamiento y a la imagen de José Gabriel Condorcanqui Noguera cuyas características tuvo ribetes propios de un ícono de la cultura pop ${ }^{(2)}$ hasta las actuales investigaciones que plantean los hechos de 1780 "como un tiempo en el cual ya se manifiestan diversas expresiones de protesta, las cuales desembocan en la lucha independentista"

1 Denominado así al periodo que comprendió en gobierno militar de facto del General EP Juan Velasco Alvarado entre 1968 y 1975.

2 El autor del logo de Túpac Amaru II, que fuera parte de la promoción y difusión de la Reforma Agraria, fue el diseñador y publicista peruano Jesús Rey Durand. 
(Guerra 2016:11). Empero este trascendental hecho histórico, que resulta muy vasto y rico en fuentes, no ha sido explotado en su totalidad pues a las perspectivas ya conocidas como la económica, política y social se han sumado pocos intentos novedosos como el uso de la ucronía como ejercicio retrospectivo para entender este particular proceso histórico como lo hiciera el insigne José Agustín de la Puente Candamo (2017) o Charles Walker (2012) en sendos artículos. En tal sentido, y para motivar el debate, es posible añadir una mirada que parta desde una visión particular de los hechos. Es decir desde la aseveración de un testigo presencial cuyas reflexiones no se circunscriben a un documento oficial sino a sus propias experiencias, asimismo, la de aquellos personajes ordinarios (mujeres, hombres, ancianos, pobladores, soldados, campesinos, etc.) que la Historia suele empaquetar en un gran bloque o simplemente olvidar. En virtud a ello, a través de estas líneas, se escudriña un documento intitulado "Carta de Don Juan Bautista Zavala vecino de La Paz en que continuan exponiendo las calamidades de dicha ciudad"(3) (NCDIP 2017:427-43) que da cuenta del testimonio de primera mano de un poblador de aquella intendencia del Virreinato del Río de la Plata en 1782 quien reflexiona sobre sí mismo y su entorno ante la situación adversa que produce graves estragos e infortunios que afectaron a su familia y su comunidad, además, la desazón e impotencia que sintió ante el accionar violento de los rebeldes, la inoperancia y corrupción de los militares y los funcionarios españoles contra su soberano que se produjeron durante la etapa final de la "insurreción de Túpac Amaru II en el Cusco" (Porras, 1963: 279).

3 El documento comprende tres cartas privadas escritas el 2, 3 y 15 de enero de 1782 remitidas desde la nueva Intendencia de La Paz que fuera parte del Virreinato del Río de la Plata desde 1776.

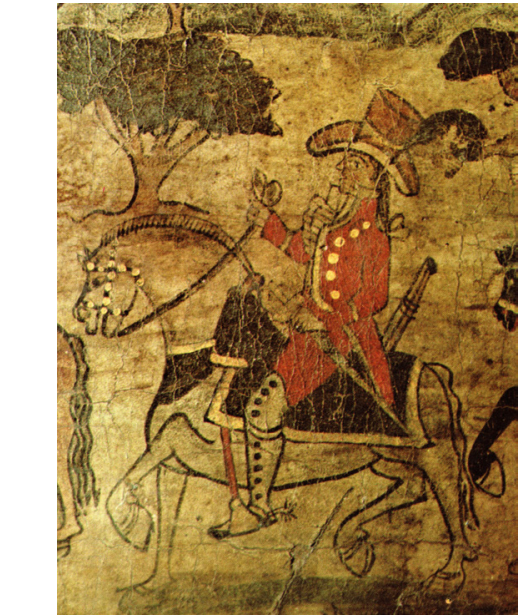

Túpac Amaru II, según Pablo Macera (1975),

\section{CONTEXTO HistóRico}

Eran los tiempos del reinado de Carlos III de España de la Real Casa de Borbón quien, a su turno, nombró a Agustín de Jáuregui y Aldecoa como el trigésimo tercer virrey del Perú. Este hizo su arribo al territorio colonial el 19 de julio y el 21 del mismo, de 1780, asumió el cargo en reemplazo de Manuel de Guirior. A la sazón la situación en el Virreinato del Perú no era auspiciosa para la nueva autoridad en lo absoluto tal y como refirió al respecto Ricardo Palma: “(...) francamente, que ninguno de sus antecesores recibió el mando bajo peores auspicios" (1893: 341), pues se tenian noticias de diferentes rebeliones contra "las aduanas, las alcabalas, los corregidores, los malos funcionarios y las revisitas" (Guerra, 2016:40) como lo fue también la "Conspiración de los plateros" en Arequipa y en Cusco la cual fue encabezada por Lorenzo Farfán de los Godos en enero de 1780. Meses después, en ese mismo sentido, el curaca de Pampamarca, Tungasuca y Yanaoca (a $80 \mathrm{~km}$ al sureste del Cusco) $)^{(4)}$

\footnotetext{
4 Según el estudio O’Phelan “Túpac Amaru II, era, al estallar la insurreción, cacique interino de Tungasuca, Pampamarca y Surimana, pueblos ubicados en la provincia de Tinta, también denominada indistintamente Canas y Canchis" (2014:3-4)
} 


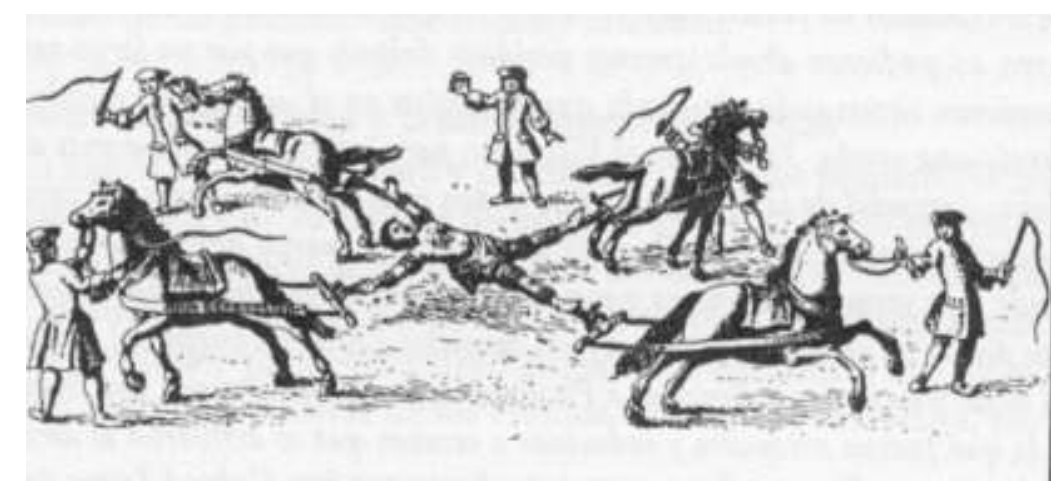

“Ejecución de Túpac Amaru II”. Grabado anónimo (s/f). Imagen: Dominio público

(Walker, 2015:19), José Gabriel Condorcanqui Noguera quien también se hacía llamar "Josef Gabriel Tupac Amaru" (NCDIP, 2017:429) "para resaltar su lineaje inca" a decir de Walker (2015:19) o "Chepe" como cariñosamente lo llamaba su esposa Micaela Bastidas, inició un alzamiento el 4 de noviembre de 1780 con la captura y posterior ejecución del corregidor de Tinta, Antonio de Arriaga el 10 de noviembre del mismo año en Tungasuca. Luego de expandir el movimiento y causar zozobra en buena parte del sur andino Túpac Amaru II fue capturado en el pueblo de Langui, el 7 de abril de 1781, por el mestizo Francisco Santa Cruz y entregado a las autoridades, asimismo, fue apresada una parte de su familia ${ }^{(5)}$ y sus lugartenientes quienes, en sumario juicio, fueron sentenciados a muerte cuya pena se hizo efectiva en la plaza principal del Cusco el 18 de mayo de 1781.

5 La familia nuclear de Túpac Amaru II estuvo compuesta por su esposa Micaela Bastidas y sus hijos: Hipólito, Mariano y Fernando. Este último, por ser aún niño, fue condenado al destierro en África sin que se cumpla dicha condena terminando sus días en España. Al respecto Edgar Montiel (2011) escribió un revelador artículo intitulado "Fernandito Túpac Amaru. La historia olvidada del niño mártir" que da cuenta de una penosa y sucinta misiva remitida por el infortunado al Rey Carlos IV. En: http:/ / www.librosperuanos. com / autores / articulo / 00000002039 / Fernandito-TupacAmaru-La-historia-olvidada-del-nino-martir. De los tres hijos de "Chepe" solo Hipólito fue ejecutado aquella fatídica tarde.
UN NUEVO ESCENARIO PARA LAS ACCIONES REBELDES

Ante la muerte de Túpac Amaru II, y su grupo más cercano, asumió el liderazgo de la rebelión Diego Cristóbal Condorcanqui Castro llamado también Diego Cristóbal Túpac Amaru, primo de "Chepe", quien junto a Julián Apaza o Túpac Katari trasladarían el escenario de la rebelión a las zonas adyacentes al Alto Perú como los alrededores del Lago Titicaca o "Laguna de Chucuito" (Unanue, 1793 (1985)), la cual contaba con menos presencia del Estado español o de la Iglesia (Walker, 2015:191), La Paz y el resto del Altiplano que correspondían al recien creado Virreinato del Río de la Plata ${ }^{(6)}$ o "Virreinato de Buenos Aires" (Unanue, 1793 (1985)). En tal sentido las acciones bélicas continuaron con la ocupación, el 26 de mayo de 1781, de Carabaya así como el inicio de un largo asedio sobre La Paz de manos de Túpac Katari quien levantó el primer cerco sobre dicha Intendencia el 31 de julio del mismo año.

Mientras tanto en Lima en la Real y Pontificia Universidad de San Marcos, el 27 de agosto

\footnotetext{
$6 \quad$ Al crearse el Virreinato del Río de la Plata en 1776, separado del Virreinato del Perú, se crean las Intendencias de la Plata, Potosí, Cochabamba (comprendida Santa Cruz de la Sierra y las gobernaciones de Mojos y Chiquitos), además, de La Paz en 1782. También el territorio de Puno pasó a formar parte de aquel virreinato como Intendencia desde 1784 hasta 1796, año en que volvió a los dominios del Virreinato del Perú.
} 

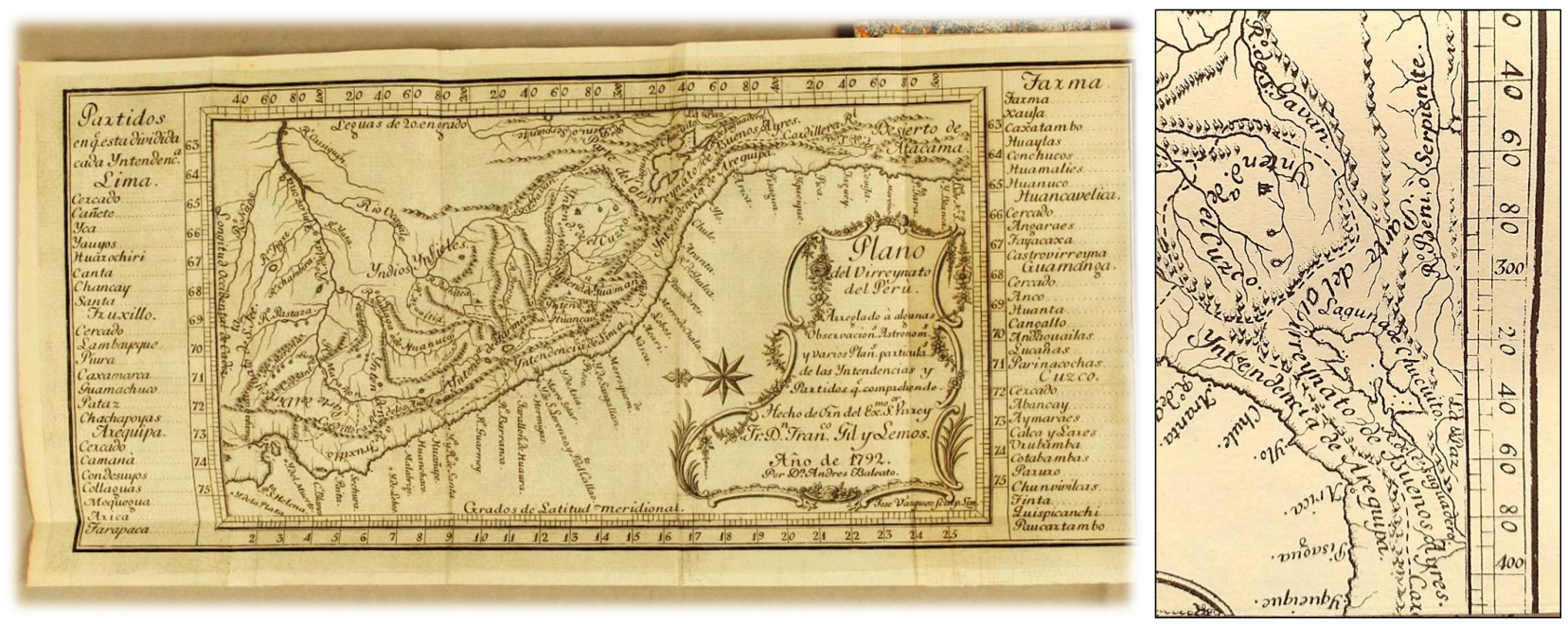

La Intendencia de La Paz (parte de Virreinato del Río de la Plata) se convierte en el escenario de la parte final de la rebelión. Figura: Plano del Virreynato del Perú de 1792 por Andrés Baleato en Guía Política, Eclesiástica y Militar del Virreynato del Perú, 1793

(Fuente: Biblioteca personal).

de 1781, el fiscal protector interino de los Naturales del distrito de la Real Audiencia de Lima y catedrático de Vísperas de Leyes, José Javier Leandro de Baquíjano y Carrillo de Córdoba, III conde de Vistaflorida ofreció su afamado Elogio de recibimiento dirigido al virrey Jáuregui donde, entre otras cosas, recalcó que "redobla en los corazones el ardor de la venganza" (1781:50) la cual se alimenta del “(...) odio pintado á la America anegada en la sangre de sus propios hijos, asesinados en las plazas públicas (...)" (Baquíjano, 178:50), además hizo una crítica a la situación de "desorden" que atravesaba el virreinato producto de la "sedición" la cual debia ser controlada, pero de forma inteligente y no con las formas que manda la "sangrienta política" (Baquíjano, 1781:54), asimismo, señaló que

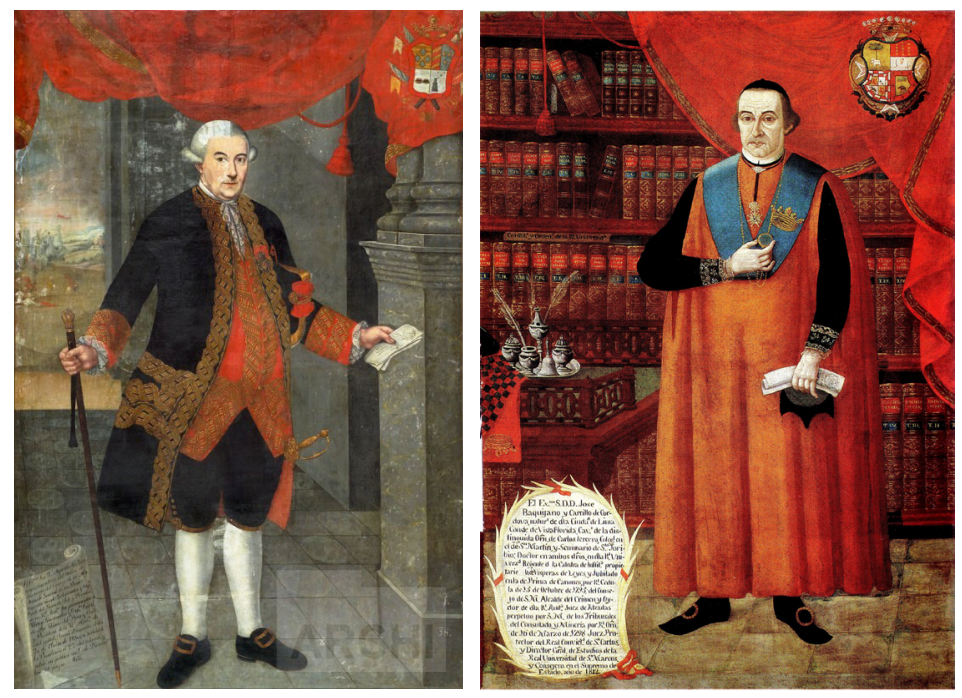

Agustín de Jáuregui, 33 virrey del Perú (iqz.) y José Baquíjano y Carrillo, catedrático de leyes en la Real y Pontificia Universidad de San Marcos (der.). Imágenes: ARCHI-MALI, MA-UNMSM 
"la vida del ciudadano es siempre preciosa y respetable: que detruir á los hombres no es ganancia, ni aquella paz apreciable á que debe aspirar la guerra" (Baquíjano, 1781:54) en alusión, aunque algo velada, a los crímenes acaecidos en el Cusco como lo plantea Raúl Porras (1969:35). Entre tanto, en las postrimerías de 1781, Túpac Katari levantó el segundo sitio impuesto sobre La Paz, el 17 de octubre, lo que se convertiría en su última acción rebelde pues al poco tiempo sería capturado y condenado a descuartizamiento siendo ejecutado el 13 de noviembre de 1781 .

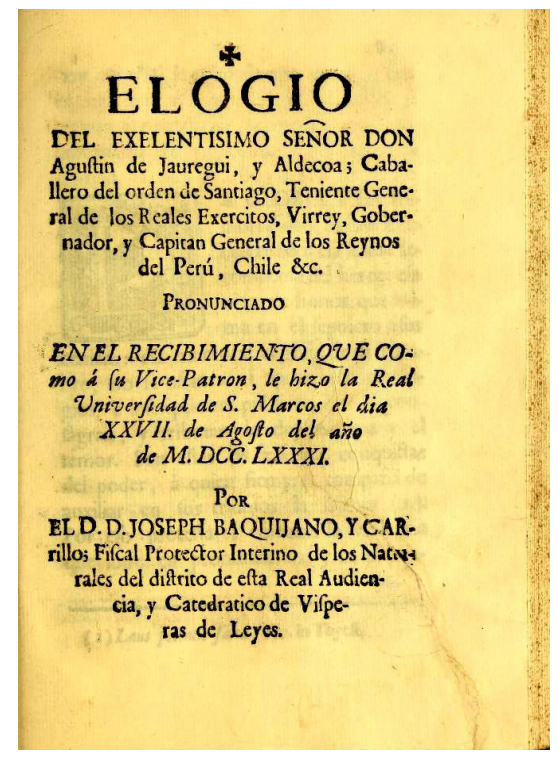

Portada del Elogio ofrecido por Baquíjano a Jáuregui el 27 de agosto de 1781. Imagen: John Carter Library.

\section{UN TESTIMONIO DESDE DENTRO}

En ese contexto, enero de 1782 marcó el inicio del final para la rebelión iniciada en el Cusco por Túpac Amaru II, hecho que trajo consigo un gran impacto político, económico y sobre todo el adveminiento, parafraseando el título de un ensayo de Jorge Basadre, de una "gran emoción social" que caló profundamente en cada mujer, hombre, anciano, poblador, rebelde, soldado, campesino, etc. Por ello resulta interesante una mira íntima de los hechos, desde una perspetiva histórica, que permita entender mejor aquella emoción social que se refleja en los testimonios, reflexiones, críticas y recomendaciones, expresadas a través de cartas, sonetos, panfletos, entre otros, que los protagonistas generaron como subproducto de las consecuencias de aquellos hechos que les tocó vivir.

De esta manera se presenta el testimonio de Juan Bautista Zavala ${ }^{(7)}$, poblador de La Paz, quien a través de tres cartas fechadas el 2, 3 y 15 de enero de 1782 relata a un amigo no identificado sus impresiones sobre el estado calamitozo en el que se encontraba la "infeliz" ciudad (La Paz) como resultado de las acciones de los rebeldes y de los propios españoles.

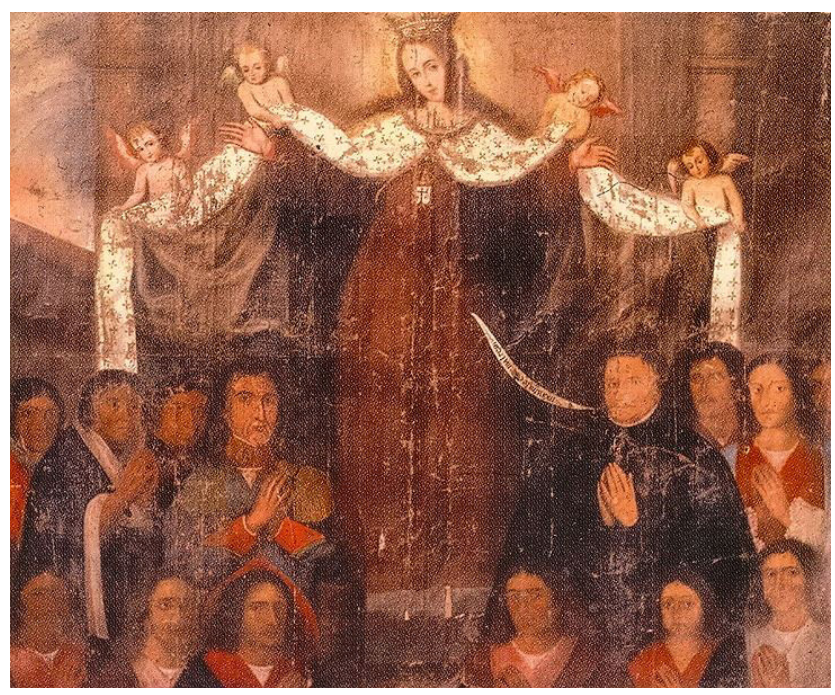

Virgen del Carmen con la familia Túpac Amaru II. Óleo. Siglo XVIII (Iglesia de Yanaoca-Cusco). Imagen: Dominio público.

7 En lo sucesivo se hará mención solo al apellido "Zavala" para referirse al personaje objeto de este estudio. 
EPISTOLARIO ZAVALA

2 DE ENERO: "Amigo, nuestras miserias siguen adelante y seguiran (...)" (NCDIP, 2017:427).

Es como Zavala inicia su misiva, dirigida a un amigo, en la que transmite toda su preocupación y desazón ante una situación a la que no encontraba visos de pronta solución. De estilo llano y fluido, Zavala, identifica de forma perspicaz que los problemas no provienen solo de los rebeldes sino que también parten de los propios funcionarios y militares españoles. De esta manera da cuenta que al desarrollarse el segundo sitio sobre de La Paz, impuesto por Túpac Katari en octubre de 1781, no se obtuvo una óptima respuesta de parte de los "Comandantes que vinieron con título de auxiliadores" pues ellos simplemente no cumplían con su misión alegando diferentes problemas debido a que no se podían mantener en esos parajes. Otro aspecto mencionado por Zavala fue el correspondiente al "memorable oficial" teniente coronel Josef Reseguin quien haciendo "su negocio particular", al transportar cargas de harina, se retiró hacia Oruro llevándose consigo "la mayor parte de las tropa de su comando, y sin haber disparado un fusil, ni hecho el menor servicio al Rey" (NCDIP, 2017:427). Esta situación produjo en Zavala una gran contrariedad que expresó de la siguiente manera: "Asi caminan las cosas de nuestro amado Soberano en estos parajes. Todos sabemos que tenemos un Rey Santo; pero que tiene la desgracia de tener pocos Comandantes que miren su real servicio (...)" (NCDIP, 2017:427). No cabe duda que Zavala habia identificado, plenamente, la otra parte del probema que en su conjunto, rebeldes y militares, se traducían en fuertes estragos sobre la población local como el desabastecimiento de productos alimenticios (harina, azúcar, vino, coca, etc.), que a su vez produjo el alza de los precios por ende una grave crisis económica y demográfica que llevó a la población a trasladarse en busca de un lugar mejor donde subsistir como fue el caso de los pobladores de la provincia de Chulumaní. Otro aspecto revelador que trasnmite Zavala es la crítica por el trato endeble de los militares hacia los rebeldes a quienes, refiere, "los jefes (militares) estan persduadidos que con dulzura reduciran a los indios rebeldes a la obediencia de Nuestro Soberano" hecho que lo lleva a una reflexión, que se condice con el modus operandi del inconsciente colectivo de ribetes tiránicos propio de la época entendida también como "una guerra de razas o de castas" (Contreras \& Zuloaga, 2016:158). En ese sentido desliza una sugerencia de solución: "el indio será bueno con el continuo castigo no permitiendoles que esten ociosos ni menos que tengan plata que esta solo les sirve para sus borracheras y causar rebeliones" y remata "en adelante deben pagar tributo doble al Rey" (NCDIP, 2017:428). Zavala va más allá y comparte con su amigo una serie de sentencias de extrema dureza que debían aplicarse contra los "indios rebeldes" en la que, sugiere, el Rey deberia quitar las tierras a las comunidades para venderlas a los españoles y sujetar a los indios al "Santo Oficio de la Inquisición, por que en el día tienen mas malicia que nosotros, y quemar las leyes de indias", además, y para el correcto cumplimeinto de estas medidas, sugirió el restablecimiento del orden militar que a su entender se lograría con "porne el Rey 200 hombres de tropa arreglada en cada provincia y que esta gente permanezca siempre, para de este modo hacer respetable el glorioso nombre de Nuestro Soberano" (NCDIP, 2017:428) y advierte a su amigo que de no tomar medidas "estaremos siempre expuestos a iguales rebeliones" pues consideraba que "el indio tan enemigo será del Alcalde Mayor, como lo ha sido del Corregidor y de todo español (...)" (NCDIP, 2017:428). 
Concluye este primer testimonio contando el pesar que sentia por la muerte de su sobrino, Josef Tomas de Zabala, en medio de una emboscada acaecida el 19 diciembre de 1782 cerca del campamento de Obejuyo. Empero la tristeza que expresa es posible colegir que esta muerte lo llenó de orgullo pues resalta el carecter glorioso del hecho y de como su sobrino había luchado con ardor en la batalla al eleminar a "mas de 300 indios" demostrando así su compromiso con la causa realista.

3 DE ENERO: "Si estas maldades no se castigan no se cuales deben ser castigadas" (NCDIP, 2017:429).

A través de una segunda misiva, Zavala, narra a su amigo un hecho que llama la atención y concita interés por referirse a Mariano Túpac Amaru, segundo hijo de "Chepe", a quien se le había otorgado el indulto ${ }^{(8)}$ "a consecuencia del perdon librado por ese Sor. Virrey a favor de los indios" (NCDIP, 2017:429) y que fue concedido por el Comandante Segurola. Otro aspecto de interés es la percepción que esta noticia causó en Zavala quien califica a Mariano como "insolente" y lo responsabiliza por la devastación del pueblo de Zorata, la muerte de 600 españoles, el bloqueo de aguas, el saqueo de pueblos y la destrucción de puentes y otras calamidades ${ }^{(9)}$ que llevaran a identificarlo como un "facineroso" que al parecer poco o nada le importaba algún tipo de censura o pena (Burns, 1992). Ante esta

8 Mariano, segundo hijo de la familia Condorcanqui Bastidas, no fue capturado y ejecutado junto a la familia nuclear el 18 de mayo de 1781. Él corrió otra suerte pues fue indultado en enero de 1782 en virtud al tratado de paz que su tío, Diego Cristóbal Túpac Amaru, concertara con las fuerzas realistas.

9 Este forajido comportamiento, al parecer, fue continuo pues luego de obtener el indulto Mariano protagonizó un escandaloso hecho, además de lo narrado por Zavala, al atacar el convento de Santa Catalina del Cusco para secuestrar a María Mejía en agosto de 1782 con quien quería casarse. En Burns, K. (1992). “Amor y rebelión en 1782: El caso de Mariano Túpac Amaru y María Mejía”. Histórica, 131-176. situación no esconde su más pura indignación al reclamar, con su pluma, un castigo para los responsables, asimismo, deslizó la idea de una autoridad (Estado) distante de la precaria situcación por la que atravezaban sumado al desconocimiento de la verdadera situación de indios y súbditos. Zavala concluye esta epístola compartiendo su permanente estado de desazón: "Yo no entiendo las cosas de nuestro gobierno español; y hemos llegado al estado de que la Nacion mas baja del mundo nos de la ley" (NCDIP, 2017:429).

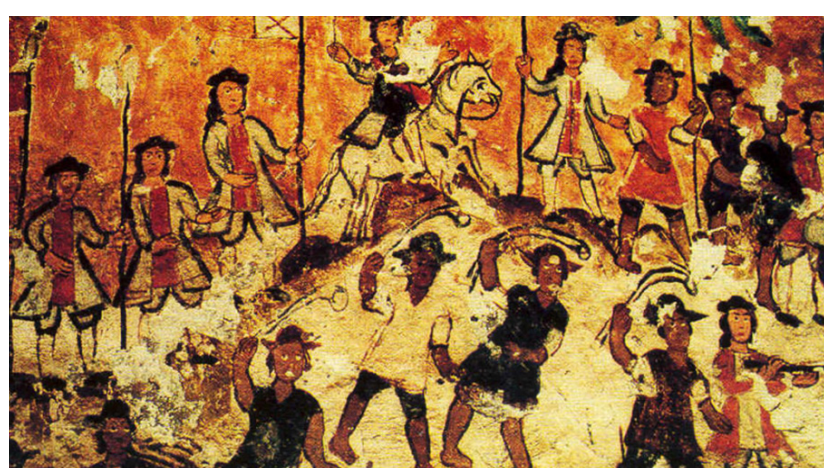

La rebelión fue continuada por Diego Túpac Amaru y Túpac Katari en las zonas adyacentes al Alto Perú encontrando resistencia del comandante Sebastián Segurola.

Imagen: Diario Los Andes de Puno.

15 DE ENERO: “Amigo, las cosas de nuestra España caminan con mucha flema y esta es la causa de nuestra perdición" (NCDIP, 2017:430).

Esta última misiva nos presenta a un Zavala con mayor pesadumbre ante la situación pues la rebelión no se apagaba y continuaba tenazmente sobre la provincia de Chucuito y Chulimaní. Lo que condujo a Zavala, sumado a lo ya mencionado, señalar un elemento más al que hizo hincapié cuando escribió "nuestra flaqueza o la cobardia española" (NCDIP, 2017:430). Tal vez con ello encontraba una explicación lógica a la desidia de los realistas ante el embate de los rebeldes que continuaban haciendo de las suyas. A esto se sumó el 
abandono del Estado al momento de pertrechar sus tropas como lo escribió Zavala con aquella indignación como un sello indeleble: "Nuestro Virrey el Sor Vertiz va para dos años que hizo salir de Buenos Aires porción de fusiles para estas provincias, las cuales hasta la fecha no han llegado, ni tampoco se sabe su paradero" (NCDIP, 2017:430) hecho que afectó la defensa del poblado de Chulumaní lo cual reafirmó la idea de una autoridad distante, pasiva y alejada de la realidad y las necesidades de la población que llevó a Zavala a compartir con su amigo una visionaria reflexión: "la revelion va creando muchas raíses y nuestros Comandantes las van cultivando en los mismos términos que las cultivaron los Comandantes británicos en sus americas".

Zavala, sin lugar a dudas, entendió claramente la situación que lo llevó a infundir en sí mismo grandes temores los cuales expresaba a través de sus reflexiones que eran únicamente correspondencia directa de los hechos. Como corolario de todas las calamidades vividas, Zavala dirige una furibunda queja final hacia los que gobiernan encontra del propio Rey. Con ella criticaba el actuar de los funcionarios coloniales que identifica como el verdadero motivo de los males, que Serulnikov señala como "blanco primordial del descontento campesino" (Serulnikov, 2006:238), al afirmar, además, que la corrupción campeaba en todo su esplendor y los intereses nacionales eran dejados de lado. Escribió al respecto: "En el día se ha envilecido por que el honor que tanto apreciaban lo han abandonado y en su lugar han subrogado el robo y la adulación" (NCDIP, 2017:431).

Concluye esta misiva con un viso de luz de esperanza al final del túnel cuando menciona que "nuestro Comandante es el unico que puede descirse tiene amor al servicio de nuestro Soberano, y al bienestar del Estado"
(NCDIP, 2017:431). Aquí Zavala hizo referencia al Comandante Segurola quien dispuso un pequeño ejército del mil hombres con el cual libró a la población del tercer sitio sobre $\mathrm{La}$ Paz, además, de lograr posteriores resultados positivos contra los rebeldes.

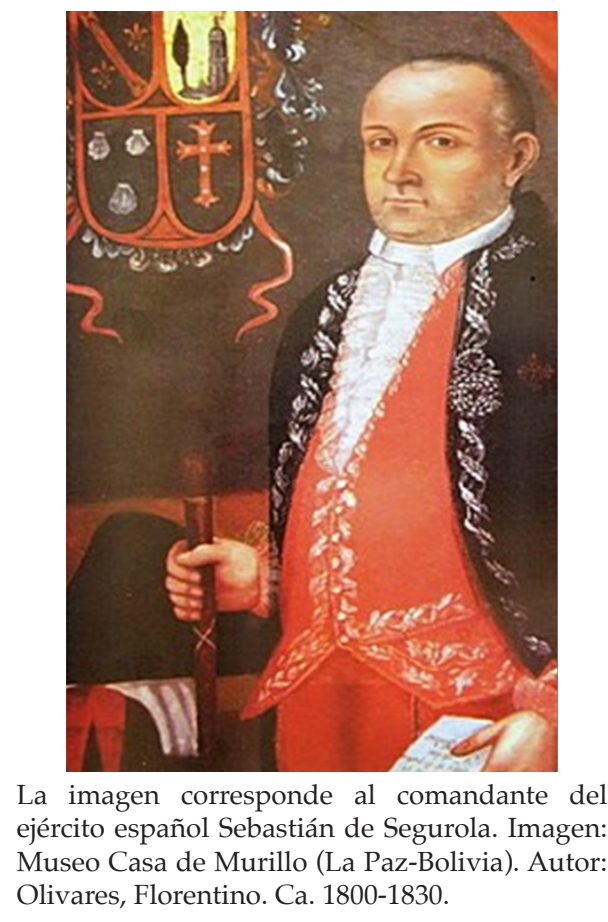

\section{A Modo De Conclusión}

El testimonio epistolar de Juan Bautista Zavala, vecino de la intendencia de $\mathrm{La} \mathrm{Paz}$, resulta en muchos pasajes revelador por pertenecer a una persona sin autoridad política, militar o religiosa sino a un poblador común que reflexiona sobre su entorno ante la trágica situación que le tocó vivir. Si bien es cierto que en estas tres misivas no se precisa una clara definición de la procedencia social de Zavala existen algunas pistas que permiten identificar ese "espíritu de posesión" (Lavallé, 1993:23) que se imprime en su relato al expresar, por citar un ejemplo, sus preocupaciones ante las penurias que sufrió su localidad y que él refiere como "cosas de nuestra España" 
(NCDIP, 2017:430) sin hacer distinción alguna entre la metrópoli y las posesiones de ultramar considerando el problema como un todo lo que no hace más que reflejar aquel carácter de identificacón, representación o sentido de pertenecia basado en un "sistema de apreciación" (Vovelle, 2003:18), el cual se determina por las modalidades de observación del entorno y de sí mismo o de su grupo social en conformidad al entremado sociocultural que organiza sus vínculos afectivos, que para este caso en particular lo autodefine como súbdito realista más allá de ser español, indio noble o criollo. Hecho que, a su vez, le permite, por que así se lo dicta su sentido de pertenecia, reclamar ante la inoperancia y distancia de los funcionarios del Estado encarnado en la actitud endeble de la milicia y la indiferencia y corrupción de los funcionarios estatales coloniales para con su Soberano.

En suma, Zavala, un poblador común, se convierte en un agente dinamizador mediante el cual es posible analizar y entender el significado histórico de los hechos descritos desde su particular punto de vista. Hechos que lo llevan a concebir una prospectiva sombría de su devenir y su entorno lo que convierte esta experiencia personal expresada a través de epístolas en un testimonio que, si bien es cierto encaja con el modelo representativo del pensamiento común entre los criollos que soportaron el asedio del movimiento insurgente acaecido en La Paz en 1782 durante la etapa final de la revolución iniciada por Túpac Amaru II, no deja de ser revelador pues al expresar su consabida desazón pudo ella influir, de alguna $u$ otra manera en fondo y forma, sobre los receptores de aquellas reflexiones en un momento tan convulso para el ya complicado entramado social del sur andino de fines del siglo XVIII y que, además, el propio Zavala relacionaba proféticamente con aquel accionar de los "comandantes británicos en sus Américas" quienes, a la sazón, estaban a punto de perder sus dominios de ultramar.

FUENTES IMPRESAS

1. Baquíjano, J. (27 de agosto de 1781). John Carter Brown Library. Obtenido de John Carter Brown Library: https: / / archive.org/ details/elogiodelexelent00baqu/page/54

2. NCDIP. (2017). Carta de Don Juan Bautista Zavala vecino de La Paz en que continuan exponiendo las calamidades de dicha ciudad. En La Rebelión de Túpac Amaru II (Vol. 4, págs. 427431). Lima: Fondo Editorial del Congreso del Perú, UPC, ACUED.

REFERENCIAS BIBLIOGRÁFICAS

1. Burns, K. (1992). Amor y rebelión en 1782: El caso de Mariano Túpac Amaru y María Mejía. En Histórica (págs. 131-176). Lima: PUCP.

2. Carlos Contreras \& Marina Zuloaga. (2016). Historia mínima del Perú. Lima: Turner \& Colegio de México.

3. Guerra, M. (2016). Cronología de la Independencia del Perú. Lima: IRA-PUCP.

4. Lavallé, B. (1993). Las promesas ambiguas. Criollismo colonial en los Andes. Lima: IRA-PUCP.

5. Montiel, E. (diciembre de 2011). librosperuanos.com. Obtenido de librosperuanos.com: http:/ / www.librosperuanos.com/ autores / articulo / 00000002039/Fernandito-Tupac-Amaru-Lahistoria-olvidada-del-nino-martir

6. O'Phelan, S. (2014). La Independencia en los Andes. Lima: Fondo Editorial del Congreso del Perú.

7. Palma, R. (1893). El Corregidor de Tinta. Crónica de la época del trigésimo tercio Virrey. En R. Palma, Tradiciones Peruanas (págs. 338-342). Barcelona: Montaner \& Simón.

8. Porras, R. (1963). Fuentes Históricas Peruanas. Lima: Minerva.

9. Porras, R. (1969). El sentido tradicional en la Literatura Peruana. Lima: Minerva.

10. Puente, J. d. (2017). Entre la fidelidad y la ruptura. En C. \&. (editores), La Independencia del Perú. ¿Concedida, conseguida, concebida? (págs. 169-191). Lima: IEP.

11. Serulnikov, S. (2006). Costumbres y reglas: racionalización y conflictos sociales durante la era borbónica. En S. Serulnikov, Conflictos sociales e insurrección en el mundo colonial andino. El norte de Potosí en el siglo XVIII (págs. 175-239). Buenos Aires: FCE.

12. Unanue, H. (1793 (1985)). Guia Política, Eclesiàstica y militar del Virreynato del Perú (facsimilar). Lima: COFIDE.

13. Vovelle, M. (2003). Aproximación a la Historia de la Mentalidades Colectivas. Lima: Fondo Editorial de la Facultad de CCSSUNMSM.

14. Walker, C. (2015). La rebelión de Tupac Amaru. Lima: IEP.

15. Walker, C. (2012). Si Túpac Amaru hubiera tomado el Cusco (1780-1781). En D. \&. (Comps.), Contra-Historia del Perú. Ensayos de Historia Política Peruana (págs. 33-47). Lima: Mitin.

Correspondencia

Ricardo Pinto-Bazurco Mendoza

rpintobazurcom@unmsm.edu.pe

FECHA DE RECEPCIÓN: 18-08-2020.

FECHA DE ACEPTACIÓN: 01-09-2020. 